\title{
Life-threatening hypophosphataemia secondary to zoledronic acid implementation in a middle-age patient who presented with advanced osteolysis in the course of multiple myeloma
}

\author{
Mikołaj Radziszewski ${ }^{1}$, Anna Karpiłowska' ${ }^{1}$, Joanna Podgórska ${ }^{2}$, Anna Ziółkowska' ${ }^{1}$, Michał Popow $^{1}$ \\ ${ }^{1}$ Department of Internal Medicine and Endocrinology, University Clinical Centre, Medical University of Warsaw, Warsaw, Poland \\ ${ }^{2} 2^{\text {nd }}$ Department of Clinical Radiology, University Clinical Centre, Medical University of Warsaw, Warsaw, Poland
}

Key words: hypophosphataemia; zoledronic acid; osteolysis; multiple myeloma

\section{Case presentation}

A 40-year-old man with a history of chest pain, nausea, and palpitation was admitted to hospital due to hypercalcaemia and renal function exacerbation. On admission the patient's condition revealed signs of dehydration and tachycardia. Moreover, the patient complained of painful ribs. Laboratory tests revealed a high calcium level of $3.69 \mathrm{mmol} / \mathrm{L}$, normal parathormone $(\mathrm{PTH})-18.4 \mathrm{pg} / \mathrm{mL}$, and vitamin D deficiency - $22.14 \mathrm{ng} / \mathrm{mL}$ (Tab. 1). Serum phosphate, magnesium, potassium, and sodium were within the normal range, and there were no acid-base-balance disturbances. Abdominal ultrasound offered no important findings. However, low-dose whole-body computed tomography scanning displayed an advanced diffused osteolysis in numerous bones (Fig. 1). Additionally, some rib fractures were present. Consecutively, further biochemical analyses found mild normocytic anaemia, an elevated erythrocyte sedimentation rate of $94 \mathrm{~mm}$ and lactate dehydrogenase of $325 \mathrm{U} / \mathrm{L}$, monoclonal gammopathy features in protein electrophoresis, and a $\kappa / \lambda$ serum ratio equal to 1696.1 .

The above led to a suspicion of non-PTH-mediated hypercalcaemia (NPTH-H) in the course of multiple myeloma (MM). Treatment then included intravenous fluids, forced diuresis, and calcitonin and zoledronic acid administered following an improvement of renal function (a glomerular filtration rate of $49 \mathrm{~mL} / \mathrm{min} / 1.73 \mathrm{~m}^{2}$ ). Unexpectedly, a severe $(0.2 \mathrm{mmol} / \mathrm{L})$ hypophosphataemia with hypophosphaturia $(<0.1 \mathrm{mmol} / \mathrm{L})$ occurred four days later. Tubular reabsorption of phosphate (TRP) was within the normal range -0.895 (0.85-0.95), while the tubular maximum reabsorption rate of phosphate to glomerular filtration rate (TmP/GFR) decreased significantly to $0.19 \mathrm{mmol} / \mathrm{L}$ (1.0-1.35). On the other hand, prior to bisphosphate administration, these parameters were consecutively 0.52 and $0.43 \mathrm{mmol} / \mathrm{L}$, with phosphate concentration $0.82 \mathrm{mmol} / \mathrm{L}$ and its excretion in urine at $5.4 \mathrm{mmol} / \mathrm{L}$, together with features of mild acute kidney injury (Tab. 1). The PTH level increased slightly.

Despite the patient's relatively stable state, insufficient oral supplementation of phosphate and severity of observed hypophosphataemia accounted for resorting to the application of intravenous phosphate infusion, which was continued for four days. Concomitant treatment i.a. involved alphacalcidol and cholecalciferol.

To confirm neoplastic disease, bone marrow biopsy was performed, revealing a level of infiltration of pathological plasma cells equal to $42.7 \%$.

\section{Discussion}

Multiple myeloma is a neoplastic disease characterised by lytic lesions of bones [1]. The diagnosis is rare in adults under 40 years old (approximately 2\%), with average age at diagnosis being 70 years. MM-related hypercalcaemia is caused by osteoclast activation involving a receptor activator of the NF- $\kappa$ B (RANK) system, as accompanied by hydrogen and cytokine release - mainly of interleukin-6, sclerostin, and the glycoprotein Dickkopf-1 (DKK-1) [2]. Zoledronate therefore serves as a standard treatment because it binds to hydroxyapatite complexes at metabolically active 


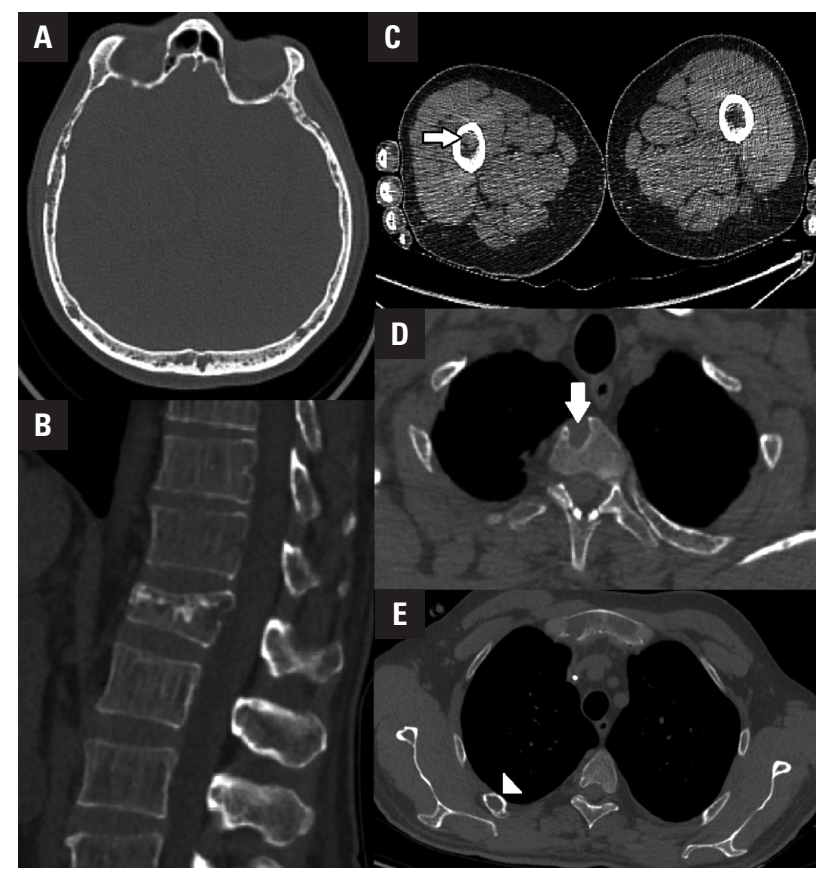

Figure 1. The whole-body CT scan reveals numerous signs of multiple myeloma. A. Axial image of the scull shows multiple lytic lesions. B. Sagittal reconstruction over the lumbar spine shows signs of osteoporosis - diffuse loss and thickening of the trabeculae in the spine and a compression fracture of lumbar vertebra (L1). C. Axial image of the lower extremities shows intramedullary soft tissue lesion in the proximal femur (arrow). D. Axial image of the chest shows well-circumscribed, lytic bone erosion in the vertebral body (arrow). E. Axial image of the chest shows erosion with scalloping of the cortical bone in the rib (arrowhead)

sites on bones. It also inhibits the farnesyl pathway in neoplastic cells [3].

Because an extremely advanced osteolysis was present in our patient, usage of zoledronate was capable of causing a calcium and phosphate release-block from bones, and this was indeed observed. Secondarily to border hypoparathyroidism-PTH suppression and a decrease in the calcitriol level, the patient had not saved phosphate prior to the zoledronate therapy. A dangerous reduction in phosphate level following bisphosphonate treatment with an increase in the TRP value would seem to confirm the association. Unlike with typical findings, we noted rare profound hypophosphataemia, seen in just $1 \%$ of cases [4]. Given the lack of phosphaturia, glycosuria, and tubular loss of other ions, Fanconi syndrome secondary to bisphosphonate use was not suspected. Nonetheless, such effects have been described in the literature [5].

In conclusion, the case presents the NPTH-H treated effectively with bisphosphonate, albeit accompanied by severe, life-threatening hypophosphataemia. Thus far, a phenomenon of this kind has not gained broad discussion in the literature. Our hypothesis implies that
Table 1. Findings of essential laboratory tests

\begin{tabular}{lcccc}
\hline Variable & Unit & Norm & $\begin{array}{c}\text { Result } \\
\text { prior to ZA } \\
\text { treatment }\end{array}$ & $\begin{array}{c}\text { Result } \\
\text { post ZA } \\
\text { treatment }\end{array}$ \\
\hline $\mathrm{Ca}$ & $\mathrm{mmol} / \mathrm{L}$ & $2.15-2.6$ & 3.69 & 1.91 \\
\hline $\mathrm{UCa}$ & $\mathrm{mmol} / \mathrm{L}$ & - & 2.7 & 0.5 \\
\hline $\mathrm{FE} \mathrm{Ca}$ & - & $0.01-0.02$ & 0.064 & 0.056 \\
\hline $\mathrm{P}$ & $\mathrm{mmol} / \mathrm{L}$ & $0.81-1.45$ & 0.82 & 0.2 \\
\hline $\mathrm{UP}$ & $\mathrm{mmol} / \mathrm{L}$ & - & 5.4 & $<0.1$ \\
\hline $\mathrm{P}$ metabolism features & & & \\
\hline \multicolumn{1}{l}{$\mathrm{TRP}$} & - & $0.85-0.95$ & 0.52 & 0.895 \\
\hline $\mathrm{TmP} / \mathrm{GFR}$ & $\mathrm{mmol} / \mathrm{L}$ & $1.0-1.35^{\mathrm{a}}$ & 0.43 & 0.19 \\
\hline $\mathrm{Mg}$ & $\mathrm{mmol} / \mathrm{L}$ & $0.7-1.0$ & 0.82 & 1.14 \\
\hline $\mathrm{PTH}$ & $\mathrm{pg} / \mathrm{mL}$ & $15.0-65.0$ & 18.4 & 30.9 \\
\hline $\begin{array}{l}\text { 25-hydroxy- } \\
\text {-vitamin D3 }\end{array}$ & $\mathrm{ng} / \mathrm{mL}$ & $30.0-80.0$ & 22.14 & $\begin{array}{c}\text { Not } \\
\text { measured }\end{array}$ \\
\hline
\end{tabular}

$\mathrm{Ca}$ - calcium; $\mathrm{FE}$ - fraction excretion; $\mathrm{Mg}$ - magnesium; $\mathrm{P}$ - phosphate; PTH — parathormone; TmP/GFR — tubular reabsorption rate of phosphate to glomerular filtration rate; TRP — tubular reabsorption of phosphate; $\mathrm{UCa}$ - urinary calcium; UP — urinary phosphate; ZA — zoledronic acid; athe norm adjusted for patient's age, according to [6]

the advanced osteolysis and mechanisms adaptive in the event of calcium and phosphate release from bones are what trigger the zoledronate effect. Also, despite zoledronate being the treatment of choice in hypercalcaemia, significant side effects may occur. It is of great importance that the observed relationship be analysed with caution, due to the slight renal dysfunction. Ion levels, TRP, vitamin D, and PTH concentrations prior to zoledronate therapy, as well as control measurements of both serum and urine phosphate, and calcium levels - with the excretion fraction throughout the first post-treatment days - would all then seem to be justified.

\section{Conflict of interest}

None declared.

\section{References}

1. Delorme S, Baur-Melnyk A. Imaging in multiple myeloma. Recent Results Cancer Res. 2011; 183: 133-147, doi: 10.1007/978-3-540-85772-3_ 7, indexed in Pubmed: 21509684.

2. Harmer D, Falank C, Reagan MR. Interleukin-6 Interweaves the Bone Marrow Microenvironment, Bone Loss, and Multiple Myeloma. Front Endocrinol (Lausanne). 2018; 9: 788, doi: 10.3389/fendo.2018.00788, indexed in Pubmed: 30671025

3. Russell RG, Watts NB, Ebetino FH, et al. Mechanisms of action of bisphosphonates: similarities and differences and their potential influence on clinical efficacy. Osteoporos Int. 2008; 19: 733-759, doi: 10.1007/s00198-007-0540-8, indexed in Pubmed: 18214569.

4. Chiam P, Manju C, Chiam P, et al. Profound and protracted hypophosphatemia after a single dose of zoledronic acid infusion for osteoporosis associated with normocalcemic primary hyperparathyroidism. Med Case Rep. 2017; 3: 1-4, doi: 10.21767/2471-8041.100059.

5. Torimoto K, Okada Y, Arao T, et al. A case of zoledronate-induced tubulointerstitial nephritis with Fanconi syndrome. Endocr J. 2012; 59(12): 1051-1056, doi: 10.1507/endocri.ej12-0166, indexed in Pubmed: 22814143.

6. Payne RB. Renal tubular reabsorption of phosphate (TmP/GFR): indications and interpretation. Ann Clin Biochem. 1998; 35 ( Pt 2): 201-206, do i: 10.1177/000456329803500203, indexed in Pubmed: 9547891. 